\begin{tabular}{c} 
International Journal of Engineering \& Technology, 7 (3) (2018) 1812-1817 \\
International Journal of Engineering \& Technology \\
SPC \\
Website: $\begin{array}{c}\text { www.sciencepubco.com/index.php/IJET } \\
\text { doi: } 10.14419 / \text { ijet.v7i3.13010 } \\
\text { Research paper }\end{array}$ \\
\hline
\end{tabular}

\title{
Influence of end user development on software project estimation
}

\author{
Archana Srivastava $^{1 *}$, Dr. S. K. Singh ${ }^{2}$, Dr. Syed Qamar Abbas ${ }^{3}$ \\ ${ }^{1}$ Research Scholar, Amity School of Engineering \& technology, Amity University Uttar Pradesh, Lucknow, India-226010 \\ 2 Professor, Amity University Uttar Pradesh, Lucknow, India-226010 \\ ${ }^{3}$ Director, Ambalika Institute of Management \&Technology, Lucknow, India-226010 \\ *Corresponding authorE-mail: asahai@amity.edu, srivastavaarchana891@gmail.com
}

\begin{abstract}
Use Case Point Method (UCP) is used to estimate software development effort. UCP uses a project's use cases to produce a reasonable estimate of a project's complexity and required man hours. Advance Use Case Point Method (AUCP) is an extension of UCP. AUCP extends UCP by adding the additional effort required in incorporating end user development (EUD) features in the software for overall project effort estimation. Today user needs are diverse, complex, and frequently changing hence need of EUD is also increasing. EUD features if incorporated in the software increases end user satisfaction exponentially but incorporating EUD features increases design time complexity and increases the effort significantly based on the end users requirements. This paper provides a case study to demonstrate the comparative analysis of UCP and AUCP using paired t-test. It also observes that there can be on an average $20 \%$ increase in overall effort of development on adding EUD features.
\end{abstract}

Keywords: Use Case Point Method (UCP); Advance Use Case Point Method (AUCP); End User Development (EUD); Human Computer Interaction (HCI); End User Computing (EUC); Technical Complexity Factors (TCF); Environmental Complexity Factors (ECF)

\section{Introduction}

Estimation of object oriented software cost and effort is an important and hard management activity. This is due to the lack of information to making decisions in the early phases of the development, frequently characterized by uncertainty. To help the managers in this task, there are in the literature many estimation models that usually include two main metrics: Lines of Code (LOC) and Function Points (FP) [12], both of them with skills and limitations. LOC is dependent on the programming language and the FP Analysis (FPA) is subjective and based on human decisions [13]. The most popular technique for object-oriented software cost estimation is Use Case Points (UCP) method.

The Use Case Points Method (UCP) is an effort estimation algorithm proposed by Gustav Karner (1993). Use Cases are frequently used to describe the business process of object oriented projects. Use cases are an effective method of modeling a software system. It builds a mutual vision of the problem at hand by bridging the gap between the people who understand the problem and the people who understand how to build a solution. This method was used to produce the estimate from the project's use cases. The UCP method analyzes the project's use case, actors, scenarios and various technical and environmental factors and abstracts them into an equation [10-13].

Advantages of UCP

1) Each use case describes one way the system is used, but major benefit of use case modeling is that it also describes all of the things that might go wrong. Identifying exceptions to a successful scenario early in the project saves a lot of time by finding subtle requirements.
2) The advantage to estimating with use case points is that the process can be automated. Some use case management tools will automatically count the number of use case points in a system. This can save the team a great deal of estimating time.

3) It is also possible to establish an organizational average implementation time per use case point. This would be very useful in forecasting future schedules. Though, this depends heavily on the assumption that all use cases are consistently written with the same level of detail.

4) Another advantage to use case points is that they are a very pure measure of size. Good estimation approaches allows separating estimation of size from deriving duration. Use case points qualify in this regard because the size of an application will be independent of the size, skill, and experience of the team that implements it [10].

5) An early project estimate helps managers, developers, and testers plan for the resources a project requires. As the case studies indicate, the UCP method can produce an early estimate within 20 percent of the actual effort, and often, closer to the actual effort than experts and other estimation methodologies [11].

\section{End user development}

End user development is an interdisciplinary field that traditionally relates to areas such as psychology of programming, empirical studies in software engineering, human computer interaction. Technological trends like ubiquitous computing, tangible and embodied interaction, and the internet of things, have renewed the interest in end-user development for diverse audiences looking 
into industrial design, online communities, open innovation and crowd sourcing. EUD is inherently different from traditional software development. So supporting EUD by simple traditional approaches is often not sufficient to produce successful results.

End users usually do not have training in programming languages, formal development processes, or modeling and diagramming notations. Moreover, end users often lack the time or inspiration to learn these traditional techniques, since end users usually write code in order to achieve a short- or medium-term goal rather than to create a durable software asset that will produce a long term benefit. Consequently, supporting EUD requires providing appropriate tools, social structures, and development processes that are highly usable, quickly learned, and easily integrated into domain practice. End User Development is related to HCI fields of intelligent user interfaces, programming-by-demonstration, adaptive user interfaces and development tools [16].

End User Development features if incorporated in a software or website it enhances the quality and increases end user satisfaction. EUD features enhance End User Satisfaction, User satisfaction refers to the quality product, system or tool that is able to satisfy specific requirements of the end user. User satisfaction with an application has been defined as 'the affective attitude towards a particular computer application by an end user who interacts with the application directly' [7]. End users concerned are not professional developers but have sufficient knowledge of their respective domains and like to do coding or use various wizards to customize things as per their own requirements. EUD research mainly focuses on approaches for lowering the barrier of entry to software development. Such approaches cover a wide spectrum, from enhancing the macros and spreadsheets that millions use every day to sophisticated algorithms that create programs by example without ever exposing the user to textual code [11].

Demand of EUD is everywhere including the social networking sites. All active social network users produce and shares texts, images and videos. While developers can access such data through application programming interfaces (APIs) for creating games, visualizations and routines, end users have less control on such information. Their access is mediated by the social application features, which limits them in combining sources, filtering results and performing actions on groups of elements. FaceMashup, an end user development (EUD) environment supporting the manipulation of the Facebook graph is introduced to fill this gap [3].

Despite three decades of research on software cost estimation, the research community has yet to provide a viable model for EndUser Development (EUD) environments. Hence one element of the size and effort is the additional design time expended in enduser programming [5]. None of the estimation model has included EUD development features as an additional cost driver. EUD essentially out-sources development effort to the end user. Additional EUD features increases the development effort but ensures high quality that is measured by the fulfillment of end user requirements. End User Development enhances the End user satisfaction level as users are involved throughout the development process starting from the requirement gathering to designing phase.

\section{Case study UCP}

Use Case Point Method (UCP) is as follows [4, 14]:

Let us take 5 projects and calculate UCP using the following steps.

\subsection{Classify actors}

For Simple WF (Weight Factor) $=1$, For Average $W F=2$, for Complex WF $=3$.

Unadjusted Actor Weights (UAW) $=\sum$ (Actors in each group * WF)

\begin{tabular}{|c|c|c|c|c|c|c|c|c|c|c|c|c|}
\hline \multicolumn{13}{|c|}{ Table 1: (UAW) } \\
\hline $\begin{array}{c}\text { Actor Complexity } \\
\text { level }\end{array}$ & Descripion & Weight & Projectl & Value & Project? & Value & Projects & Value & Project 4 & ralue $\mathrm{Pr}$ & Projects & value \\
\hline Simple & $\begin{array}{l}\text { Interacts throught API, as } \\
\text { Command Prompt }\end{array}$ & 1 & 2 & 2 & 3 & 3 & 8 & 8 & 5 & 5 & 8 & 8 \\
\hline Average & $\begin{array}{l}\text { Interacts through Protocol } \\
\text { asTCPIP, HTP }\end{array}$ & 2 & 4 & 8 & 2 & 4 & 1 & 14 & 5 & 10 & 5 & 10 \\
\hline Comples & $\begin{array}{l}\text { Interacts through GII of } \\
\text { Web Pgere }\end{array}$ & 3 & 3 & 9 & 8 & 24 & 6 & 18 & 5 & 15 & 10 & 30 \\
\hline & & & Provet l & 19 & Provert? & 31 & Proet3 & 40 & Proent & $30 \mathrm{P}$ & Proent5 & 48 \\
\hline
\end{tabular}

\subsection{Calculating unadjusted use case weight (UUCW)}

Use cases are classified as simple, average or complex depending on the number of transactions.

$\mathrm{UUCW}=\sum(\mathrm{Use}$ Case in each group $* \mathrm{WF})$

Table 2: (UUCW)

\begin{tabular}{|c|c|c|c|c|c|c|c|c|c|c|c|c|}
\hline $\begin{array}{c}\text { Usec Case } \\
\text { Complexitylereel }\end{array}$ & Description & Weight & Projectl & Value & Project? & Value & Project3 & Value & Project 4 & value & Project5 & ralue \\
\hline Simple & Lising 1 to 3 Transactions & j & 8 & 40 & 5 & 25 & 3 & 15 & 10 & 50 & 5 & 25 \\
\hline Average & Lising 4 to 7 Transactions & 10 & 5 & 50 & 8 & 80 & 4 & 40 & 8 & 80 & 4 & 40 \\
\hline Complex & $\begin{array}{c}\text { Using more than } 7 \\
\text { Transactions }\end{array}$ & 15 & 9 & 135 & 4 & 60 & 1 & 105 & 3 & 45 & 10 & 150 \\
\hline & & WUCW & proeet 1 & 225 & propect? & 165 & proiet? & 160 & provert 4 & 175 & proeect5 & 215 \\
\hline
\end{tabular}

\subsection{Calculate the unadjusted use case point (UUCP)}

Unadjusted Use Case Point is the sum of Unadjusted Use Case Weight (UUCW) and Unadjusted Actor Weights (UAW).

$\mathrm{UUCP}=\mathrm{UUCW}+\mathrm{UAW}$

Table 3: (UUCP)

\begin{tabular}{|c|c|c|c|}
\hline Project & UAW & UUCW & UUCP \\
\hline Project 1 & 19 & 225 & 244 \\
\hline Project 2 & 31 & 165 & 196 \\
\hline Project 3 & 40 & 160 & 200 \\
\hline Project 4 & 30 & 175 & 205 \\
\hline Project 5 & 48 & 215 & 263 \\
\hline
\end{tabular}

\subsection{Calculating the technical complexity factor (TCF)}

Technical complexity factor is calculated by using the formula

$\mathrm{TCF}=0.6+(0.01 * \mathrm{TF})$

Where

$\mathrm{TF}=\mathrm{T} 1+\mathrm{T} 2+\ldots . \mathrm{T} 12+\mathrm{T} 13$ 


\begin{tabular}{|c|c|c|c|c|c|c|c|c|c|c|c|c|}
\hline \multicolumn{13}{|c|}{ Table 4: (TCF) } \\
\hline & & & \multicolumn{10}{|c|}{ project complexity } \\
\hline $\mathrm{Ti}$ & Technical factors & Weight & Project1 & Value & Project2 & Value & Project3 & Value & Project 4 & value & Project 5 & value \\
\hline $\mathrm{T} 1$ & Distributed System Required & 2 & 1 & 2 & 2 & 4 & 1 & 2 & 3 & 6 & 5 & 10 \\
\hline $\mathrm{T} 2$ & Response Time Is Important & 1 & 3 & 3 & 4 & 4 & 1 & 1 & 4 & 4 & 5 & 5 \\
\hline $\mathrm{T} 3$ & End User Efficiency & 1 & 3 & 3 & 2 & 2 & 2 & 2 & 5 & 5 & 5 & 5 \\
\hline $\mathrm{T} 4$ & $\begin{array}{l}\text { Complex Internal Processing } \\
\text { Required }\end{array}$ & 1 & 3 & 3 & 5 & 5 & 1 & 1 & 3 & 3 & 3 & 3 \\
\hline T5 & $\begin{array}{l}\text { Reusable Code Must Be A } \\
\text { Focus }\end{array}$ & 1 & 0 & 0 & 3 & 3 & 2 & 2 & 3 & 3 & 3 & 3 \\
\hline T6 & Installation Easy & 0.5 & 0 & 0 & 3 & 1.5 & 1 & 0.5 & 2 & 1 & 5 & 2.5 \\
\hline $\mathrm{T} 7$ & Usability & 0.5 & 5 & 2.5 & 4 & 2 & 1 & 0.5 & 4 & 2 & 5 & 2.5 \\
\hline $\mathrm{T} 8$ & Cross-Platform Support & 2 & 0 & 0 & 2 & 4 & 0 & 0 & 3 & 6 & 5 & 10 \\
\hline T9 & Easy To Change & 1 & 3 & 3 & 3 & 3 & 1 & 1 & 3 & 3 & 4 & 4 \\
\hline $\mathrm{T} 10$ & Highly Concurrent & 1 & 0 & 0 & 3 & 3 & 2 & 2 & 3 & 3 & 4 & 4 \\
\hline $\mathrm{T} 11$ & Custom Security & 1 & 0 & 0 & 3 & 3 & 2 & 2 & 2 & 2 & 5 & 5 \\
\hline $\mathrm{T} 12$ & $\begin{array}{l}\text { Dependence On Third-Part } \\
\text { Code }\end{array}$ & 1 & 3 & 3 & 4 & 4 & 1 & 1 & 3 & 3 & 3 & 3 \\
\hline \multirow[t]{2}{*}{$\mathrm{T} 13$} & User Training & 1 & 0 & 0 & 3 & 3 & 2 & 2 & 3 & 3 & 4 & 4 \\
\hline & & TF & project1 & 19.5 & project2 & 41.5 & project3 & 17 & project 4 & 44 & project 5 & 61 \\
\hline \multicolumn{2}{|c|}{$\mathrm{TCF}=0.6+(0.01 * \mathrm{TF})$} & $\mathrm{TCF}$ & project1 & 0.795 & project2 & 1.015 & project3 & 0.77 & project 4 & 1.04 & project 5 & 1.21 \\
\hline
\end{tabular}

\subsection{Calculating the environmental complexity factor (ECF)}

Environmental Complexity Factor (ECF) is calculated by using the formula

$\mathrm{ECF}=1.4+(-0: 03 * \mathrm{EF})$

Where:

$\mathrm{EF}=\mathrm{F} 1+\mathrm{F} 2+\ldots+\mathrm{F} 7+\mathrm{F} 8$

Table 5: (Environmental Factors)

\begin{tabular}{|l|l|c|c|c|c|c|c|c|c|c|c|c|}
\hline \multicolumn{10}{|c|}{ Table 5: (Environmental Factors) } \\
\hline Fi & Environental factors & Weight & Project1 & Value & Project2 & Value & Project3 & Value & Project4 & value & Project5 & value \\
\hline F1 & Familiar with Objectory & 1.5 & 5 & 7.5 & 4 & 6 & 1 & 1.5 & 3 & 4.5 & 4 & 6 \\
\hline F2 & Part time workers & -1 & 0 & 0 & 1 & -1 & 1 & -1 & 3 & -3 & 3 & -3 \\
\hline F3 & Analyst capability & 0.5 & 5 & 2.5 & 4 & 2 & 2 & 1 & 4 & 2 & 5 & 2.5 \\
\hline F4 & Application experience & 0.5 & 0 & 0 & 2 & 1 & 4 & 2 & 3 & 1.5 & 5 & 2.5 \\
\hline F5 & Object oriented experience & 1 & 5 & 5 & 3 & 3 & 4 & 4 & 3 & 3 & 5 & 5 \\
\hline F6 & Motivation & 1 & 5 & 5 & 3 & 3 & 4 & 4 & 4 & 4 & 5 & 5 \\
\hline F7 & Difificult programming langulage & -1 & 0 & 0 & 2 & -2 & 4 & -4 & 3 & -3 & 3 & -3 \\
\hline F8 & Stable requirements & 2 & 3 & 6 & 4 & 8 & 3 & 6 & 3 & 6 & 5 & 10 \\
\hline & & EF & project1 & 26 & project2 & 20 & project3 & 13.5 & project4 & 15 & project5 & 25 \\
\hline & ECF & project1 & 0.62 & project2 & 0.8 & project3 & 0.995 & project4 & 0.95 & project5 & 0.65 \\
\hline
\end{tabular}


3.6. Calculating the use case point (UCP), where: $\mathrm{UCP}=$ UUCP $*$ TCF * ECF

\begin{tabular}{|c|c|c|c|c|}
\hline Project & UUCP & TCF & ECF & UCP \\
\hline Project 1 & 244.00 & 0.80 & 0.62 & 120.27 \\
\hline Project 2 & 196.00 & 1.02 & 0.80 & 159.15 \\
\hline Project 3 & 200.00 & 0.77 & 1.00 & 153.23 \\
\hline Project 4 & 205.00 & 1.04 & 0.95 & 202.54 \\
\hline Project 5 & 263.00 & 1.21 & 0.65 & 206.85 \\
\hline
\end{tabular}

\section{Advance use case point (AUCP)}

It is an extension of UCP in which additional cost driver End user development factors are added. The method is as follows [6]:

a) Total eighteen EUD_Technical factors (EUD_TF) are identified and weights are assigned to each factor considering its impact on development. Each factor is assigned value 0 or 1 , depending on whether that feature is required or not required in the software. If the feature is required it is rated as 1 else 0 , and is multiplied by the assigned weight of EUD_TF. Take the summation of all factors.

b) Total eight EUD_Environmental factors (EUD_EF) are identified and weights are assigned to each factor considering its impact on development. Each factor is assigned value 0 or 1 , depending on whether that feature is required or not required in the software. If the feature is required it is rated as 1 else 0 , and is multiplied by the assigned weight of EUD TF. Take the summation of all factors.

c) Calculate EUD Technical Complexity Factor, EUD_TCF = $0.6+(0.01 *$ EUD_TF $)$

d) Calculate EUD Environmental Complexity Factor EUD_ECF $=1.4+(0.03 *$ EUD_EF $)$

e) $\quad$ AUCP $=$ UCP X (EUD_TCF X EUD_ECF)

Advance UCP is now calculated by taking the product of Use Case Point, End User Development Technical Complexity Factors and End User Development Environmental Complexity Factors.

\section{Advance use case point (AUCP) case study}

Suppose we have to add End user development features in the above five projects. The EUD requirements of all the projects are different.

\subsection{Calculate EUD_technical factors (EUD_TF) for five projects}

If the EUD_TF is required, it is rated as [1] else zero, and is multiplied by the assigned weight of EUD_TF. Take the summation of all factors. Following result is obtained.
Table 7: (EUD_TF)

\begin{tabular}{|c|c|c|c|c|c|c|c|c|c|c|c|c|}
\hline ED_ti & ED_IRCHICLLEACTORS & Weight & Projectl & Value & Project2 & Value & Project3 & Value & Project 4 & value & Project5: & value \\
\hline $\mathrm{TI}$ & Inbuilt system assistance & 1.2 & 1 & 1.2 & 1 & 1.2 & 0 & 0 & 0 & 0 & 0 & 0 \\
\hline T2 & Creating erewable codes & 1.4 & 1 & 1.4 & 1 & 1.4 & 0 & 0 & 1 & 1.4 & 1 & 1.4 \\
\hline T3 & Sharing resusable code & 1 & 0 & 0 & 1 & 1 & 1 & 1 & 1 & 1 & 1 & 1 \\
\hline It & Essy \& understandable codes & 1.3 & 1 & 1.3 & 1 & 1.3 & 0 & 0 & 1 & 1.3 & 1 & 1.3 \\
\hline I5 & 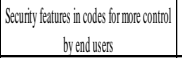 & 1.12 & 1 & 1.12 & 1 & 1.12 & 1 & 1.12 & 1 & 1.12 & 1 & 1.12 \\
\hline T6 & Authentication features & 1.3 & 1 & 1.3 & 1 & 1.3 & 0 & 0 & 1 & 1.3 & 0 & 0 \\
\hline T7 & Inbuilf ferthack baout the conretness & 1.2 & 0 & 0 & 1 & 1.2 & 1 & 1.2 & 1 & 1.2 & 1 & 1.2 \\
\hline 18 & Testable codes & 1.4 & 1 & 1.4 & 1 & 1.4 & 1 & 1.4 & 1 & 1.4 & 0 & 0 \\
\hline T) & 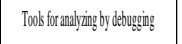 & 1.2 & 0 & 0 & 1 & 1.2 & 0 & 0 & 0 & 0 & 1 & 1.2 \\
\hline T10 & Errordetection tools & 1.3 & 0 & 0 & 1 & 1.3 & 1 & 1.3 & 0 & 0 & 1 & 1.3 \\
\hline TII & online hetep ariabiolity & 1.11 & 1 & 1.11 & 1 & 1.11 & 0 & 0 & 1 & 1.11 & 1 & 1.11 \\
\hline $\mathrm{T} 12$ & Self-eficiency & 1.20 & 1 & 1.2 & 1 & 1.2 & 1 & 1.2 & 1 & 1.2 & 1 & 1.2 \\
\hline $\mathrm{T} 13$ & Percived esse of use & 1 & 1 & 1 & 1 & 1 & 0 & 0 & 1 & 1 & 1 & 1 \\
\hline T14 & Percevied usetuluness & 1.2 & 1 & 1.2 & 1 & 1.2 & 1 & 1.2 & 1 & 1.2 & 1 & 1.2 \\
\hline$T 15$ & Fexalle codes & 1.25 & 0 & 0 & 1 & 1.25 & 0 & 0 & 1 & 1.25 & 0 & 0 \\
\hline 716 & Scaldbiliy fatutures & 1.2 & 1 & 1.2 & 1 & 1.2 & 1 & 1.2 & 1 & 1.2 & 0 & 0 \\
\hline 117 & End usertraining & 1.5 & 0 & 0 & 1 & 1.5 & 0 & 0 & 1 & 1.5 & 1 & 1.5 \\
\hline$\pi 18$ & Esse of Maintenance & 1.14 & 1 & 1.14 & 1 & 1.14 & 1 & 1.14 & 1 & 1.14 & 1 & 1.14 \\
\hline Summati & tition of EUD_ Technical factors & EUD_F & projectl & 14.57 & project2 & 22,02 & project3 & 10.76 & project 4 & 18.32 & project5 & 15.67 \\
\hline
\end{tabular}

\subsection{EUD technical complexity factor}

EUD Technical Complexity Factor (EUD_TCF) is calculated by the formula

EUD_TCF $=0.6+(0.01 *$ EUD_TF $)$

Where EUD_TF $=\mathrm{T} 1+\mathrm{T} 2+\ldots+\mathrm{T} 18$

Table 8: (EUD_TCF)

\begin{tabular}{|c|c|c|}
\hline \multicolumn{3}{|c|}{ EUD_TCF $=0.6+(0.01 *$ EUD_TF $)$} \\
\hline Project & EUD_TF & EUD_TCF \\
\hline Project1 & 14.57 & 0.75 \\
\hline Project2 & 22.02 & 0.82 \\
\hline Project3 & 10.76 & 0.71 \\
\hline Project4 & 18.32 & 0.78 \\
\hline Project5 & 15.76 & 0.76 \\
\hline
\end{tabular}

\subsection{Calculate EUD_environmental factors (EUD_EF) for five projects}

If the EUD_TF is required for the particular project it is rated as [1] else 0, and is multiplied by the assigned weight of EUD_TF. Take the summation of all factors. Following result is obtained. 


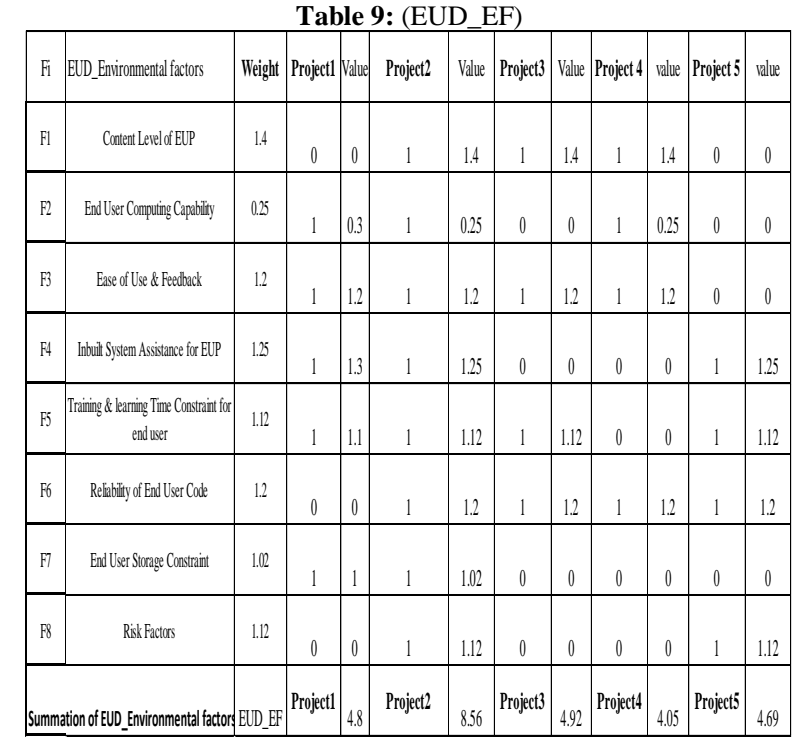

\subsection{EUD environmental complexity factor (EUD_ECF)}

EUD Environmental Complexity Factor (EUD_ECF) is calculated by the formula

EUD_ECF $=1.4+(0.03 *$ EUD_EF $)$

Where EUD_TF $=\mathrm{F} 1+\mathrm{F} 2+\mathrm{F} 3++\mathrm{F} 8$

Table 10: (EUD_ECF)

\begin{tabular}{|c|c|c|}
\hline \multicolumn{3}{|c|}{$E U D \_E C F=1.4+\left(0.03 * E U D \_E F\right)$} \\
\hline Project & $E \cup D \_E F$ & $E \cup D \_E C F$ \\
\hline project1 & 4.84 & 1.55 \\
\hline project2 & 8.56 & 1.66 \\
\hline project3 & 4.92 & 1.55 \\
\hline project4 & 4.05 & 1.52 \\
\hline project5 & 4.69 & 1.54 \\
\hline
\end{tabular}

5.5. Advance use case point (AUCP) is calculated as given below

$\mathrm{AUCP}=\mathrm{UCP} \times($ EUD_TCF X EUD_ECF $)$

Table 11: (AUCP)

\begin{tabular}{|c|c|c|c|c|}
\hline \multicolumn{5}{|c|}{ AUCP = UCP X (EUD_TCF X EUD_ECF $)$} \\
\hline Project & UCP & EUD_TCF & EUD_ECF & AUCP \\
\hline Project1 & 120.30 & 0.75 & 1.55 & 138.62 \\
\hline Project2 & 159.15 & 0.82 & 1.66 & 216.27 \\
\hline Project3 & 153.20 & 0.71 & 1.55 & 167.77 \\
\hline Project4 & 202.54 & 0.78 & 1.52 & 241.35 \\
\hline Project5 & 206.85 & 0.76 & 1.54 & 241.44 \\
\hline
\end{tabular}

\section{Result analysis}

Calculating the difference between the results of AUCP and UCP we obtain the values of table. 12 .
Table 12:

\begin{tabular}{|c|c|c|c|}
\hline UCP & AUCP & difference & \%increase \\
\hline 120.30 & 138.62 & 18.32 & 15.23 \\
\hline 159.20 & 216.27 & 57.07 & 35.85 \\
\hline 153.20 & 167.77 & 14.57 & 9.51 \\
\hline 202.54 & 241.35 & 38.81 & 19.16 \\
\hline 206.85 & 241.44 & 34.59 & 16.72 \\
\hline
\end{tabular}

These results show that the difference of AUCP and UCP is not zero. There is clear indication of increase in AUCP. It is clearly depicted in the graph Fig.1 given below.

We can further analyze the result by using paired t-test on the above values of UCP and AUCP.

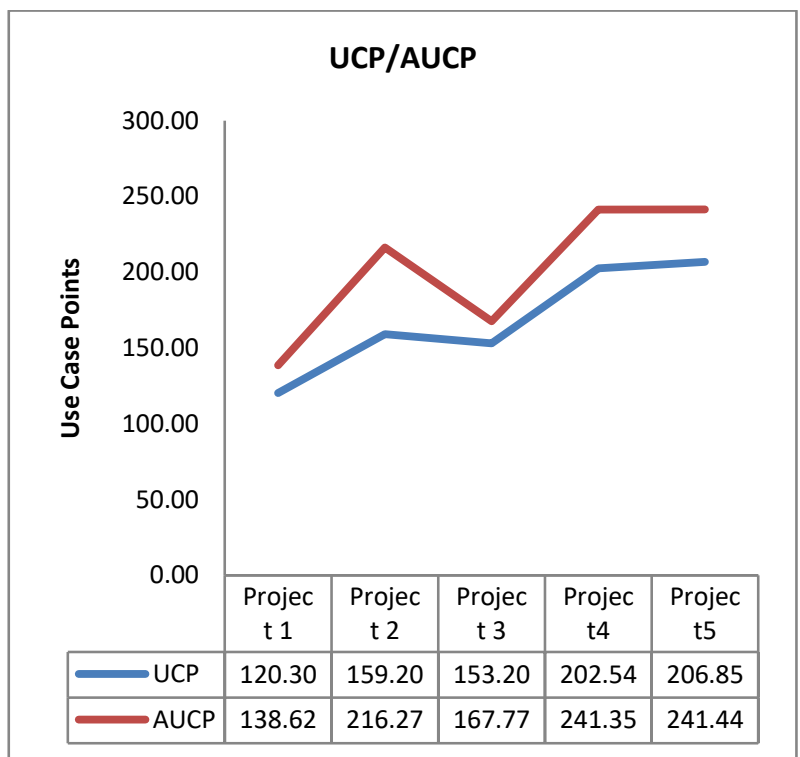

Fig. 1: Paired Sample T-Test.

The paired sample t-test, sometimes called the dependent sample t-test, is a statistical procedure used to determine whether the mean difference between two sets of observations is zero. In a paired sample t-test, each subject or entity is measured twice, resulting in pairs of observations.

Hypothesized difference (D): zero

Significance level (percentage): five

Summary statistics:

\begin{tabular}{|c|c|c|c|c|c|c|}
\hline Variable & Observations & $\begin{array}{l}\text { Obs. with } \\
\text { misising data }\end{array}$ & $\begin{array}{l}\text { Obs without } \\
\text { missing data }\end{array}$ & Minimum Maximum & Mean & $\begin{array}{c}\text { Sto. } \\
\text { deviation }\end{array}$ \\
\hline AUCP & 5 & 0 & 5 & $138.616 \quad 241.442$ & 201.090 & 46.880 \\
\hline UCP & 5 & 0 & 5 & $120,300 \quad 206.850$ & 168.418 & 36.309 \\
\hline
\end{tabular}

T-Test for two paired samples / Two-tailed test:

95\% confidence interval on the difference between the means: [11.430, 53.914], -5.699]

\begin{tabular}{|c|c|}
\hline Table 13: \\
\hline $\mathrm{t}$ (Observence & 32.672 \\
\hline$|\mathrm{t}|$ (Critical value) & 4.270 \\
\hline DF & 2.776 \\
\hline $\mathrm{p}$-value (Two-tailed) & 4 \\
\hline alpha & 0.013 \\
\hline
\end{tabular}


The number of degrees of freedom is approximated by the WelchSatterthwaite formula.

Test interpretation:

H0: The difference between the means is equal to zero.

Ha: The difference between the means is different from zero.

As the computed p-value is lower than the significance level Alpha $=0.05$, one should reject the null hypothesis $\mathrm{H} 0$, and accept the alternative hypothesis Ha.

The risk to reject the null hypothesis $\mathrm{H} 0$ while it is true is lower than $1.29 \%$.

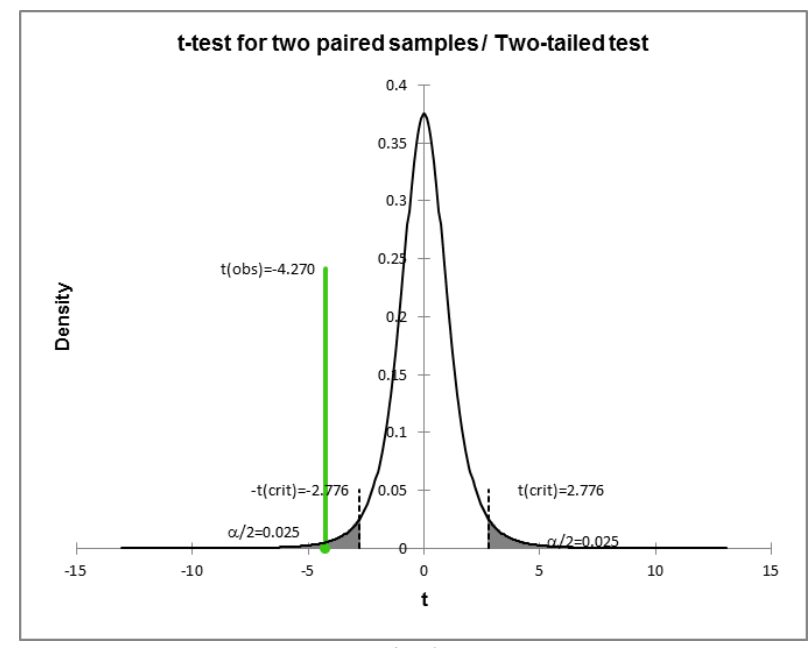

Fig. 2:

\section{Conclusion}

The results of this study provide further support for the view that when EUD features are incorporated in the system or tools it increases the size and effort. The extra interfaces and quality attributes are provided on demand to the products developed by end user for their own usage. From the result of the case study it has been found that there can be on an average maximum 20\% increase in overall effort of development. End User Software Engineering (EUSE) takes care of all quality requirements of these products. End User Development enhances the End user satisfaction level as users are involved throughout the development process starting from the requirement gathering to designing phase. As the demand of EUD features are increasing day by day its role in the overall budget cannot be ignored. As over budgeting and under budgeting both have critical consequences on the successful completion of the project. Unlike many other estimation methods, the concepts and methods behind AUCP are openly described and available for further investigation. This method will give some benefits to the developers in improving the accuracy of software effort estimation. Hence including EUD features as an additional cost driver during the estimation process will reduce the level of uncertainty involved in estimation process.

\section{References}

[1] Lieberman, H., Paterno, F., Klann, M. and Wulf, V. 2006. End-user development: An emerging paradigm. End User Development. (2006), 1-8. https://doi.org/10.1007/1-4020-5386-X.

[2] Albrecht, A. (1979). Measuring Application Development Productivity. In: Proc. of IBM Applications Developmen Symposium,pg. 83-92, October.

[3] Ghiani, G.; Paternò, F.; Spano, L.D.; Pintori, G. An environment for End-User Development of Web mashups. Int. J. Hum. Compu. Stud. 2016, 87, 38-64. https://doi.org/10.1016/j.ijhcs.2015.10.008.

[4] Resource Estimation for Objectory Projects Gustav Karner Objective Systems SF AB Torshamnsgatan 39, Box 1128, 16422 Kista, September 17, 1993.

[5] Srivastava, Archana, Syed Qamar Abbas, and S. K. Singh. "ENHANCEMENT IN FUNCTION POINT ANALYSIS." airccse.org/journal/ijsea/papers/6215ijsea01.pdf.
[6] Srivastava, A., Singh, S.K and Abbas, S.Q., ADVANCEMENT OF UCP WITH END USER DEVELOPMENT FACTOR: AUCP, International Journal of Software Engineering \& Applications (IJSEA), Vol.6, No.2, $\quad$ March 2015 https://doi.org/10.5121/ijsea.2015.6201.

[7] Gelderman, M. (1998). The relation between user satisfaction, usage of information systems and performance. Information \& Management, 34, 11-18. https://doi.org/10.1016/S03787206(98)00044-5.

[8] Lieberman, H., Paterno, F., Klann, M. and Wulf, V. 2006. Enduser development: An emerging paradigm. End User Development. (2006), 1-8. https://doi.org/10.1007/1-4020-5386-X.

[9] Ko, A.J., Abraham, R., Beckwith, L., Blackwell, A., Burnett, M., Erwing, M., Scaffidi, C., Lawrance, J., Lieberman, H., Myers, B., Rosson, M.B., Rothermel, G., Shaw, M. and Wiedenbeck, S. 2010 The state of the art in end-user software engineering. ACM Computing Surveys. (2010).

[10] Estimating With Use Case Points, Mike Cohn, Mountain Goat Software, www.mountaingoatsoftware.com.

[11] Carroll, Edward R. "Estimating Software Based on Use Case Points.” 2005 Object-Oriented, Programming, Systems, Languages, and Applications (OOPSLA) Conference, San Diego, CA, 2005.

[12] B. Anda," Comparing Effort Estimates Based on Use Case Points with Expert Estimates," 2007.

[13] C. Gence, L. Buglione, O. Demirors, P. Efe," A Case Study on the Evaluation of COSMIC-FFP and Use Case Points," 2006.

[14] Marcio Rodrigo Braz, Silvia Regina Vergilio. (2006). Software Effort Estimation Based on Use Cases, In: Proceedings of the 30th Annual International Computer Software and Applications Conference (COMPSAC'06). IEEE. M. Young, The Technical Writer's Handbook. Mill Valley, CA: University Science, 1989. https://doi.org/10.1109/COMPSAC.2006.77.

[15] Iraji, Mohammad Saber, and Homayun Motameni. "Object Oriented Software Effort Estimate with Adaptive Neuro Fuzzy use Case Size Point (ANFUSP)", International Journal of Intelligent Systems and Applications, 2012.

[16] Prabhakararao S., Cook C., Ruthruff J., Creswick E., Main M., Durham,M., And Burnett M. 2003. Strategies and behaviors of enduser programmers with interactive fault localization. IEEE Symposium on Human-Centric Computing Languages and Environments, Auckland, New Zealand, September, 15-22. https://doi.org/10.1109/HCC.2003.1260197.

[17] C. Schroth and O. Christ, "Brave new web: Emerging design principles and technologies as enablers of a global soa," in Proceedings of the IEEE International Conference on Services Computing, 2007. SCC 2007. Los Alamitos, CA, USA: IEEE Computer Society Press, 2007, pp. 597-604. https://doi.org/10.1109/SCC.2007.32. 